\title{
Produção não mercantil do espaço: domínio do tempo, antivalor e trabalho improdutivo
}

Non-commodified production of space: time domain, anti-value and unproductive labour

Producción no mercantil del espacio: dominio del tiempo, antivalor y trabajo improductivo

Production d'espace non marchande: domaine temporel, travail anti-valeur et improductif

\section{Renan dos Santos Sampaio}

\section{OpenEdition}

Journals

Edição electrónica

URL: http://journals.openedition.org/espacoeconomia/9536

DOI: $10.4000 /$ espacoeconomia.9536

ISSN: 2317-7837

Editora

Núcleo de Pesquisa Espaço \& Economia

Refêrencia eletrónica

Renan dos Santos Sampaio, «Produção não mercantil do espaço: domínio do tempo, antivalor e trabalho improdutivo ", Espaço e Economia [Online], 16 | 2019, posto online no dia 03 janeiro 2020 consultado o 10 janeiro 2020. URL : http://journals.openedition.org/espacoeconomia/9536 ; DOI : 10.4000/espacoeconomia.9536

Este documento foi criado de forma automática no dia 10 janeiro 2020.

(C) NUPEE 


\title{
Produção não mercantil do espaço: domínio do tempo, antivalor e trabalho improdutivo
}

\author{
Non-commodified production of space: time domain, anti-value and \\ unproductive labour \\ Producción no mercantil del espacio: dominio del tiempo, antivalor y trabajo \\ improductivo \\ Production d'espace non marchande: domaine temporel, travail anti-valeur et \\ improductif
}

Renan dos Santos Sampaio

\section{Introdução}

1 Este artigo é um desdobramento de um Trabalho Final de Graduação, no qual procurouse imaginar uma nova dinâmica de produção do espaço a partir da crítica da produção mercantil do espaço, que o trata como produto e como uma mercadoria fictícia. Esta produção perpetua a divisão social do trabalho, traduzida espacialmente em segregação e espoliação, gerando uma condição que chamo aqui de custo social da indústria que produz o espaço, tão determinante para as condições de vida das populações mais pobres.

2 A divisão social do trabalho não implica apenas em diferenças na hierarquia social e técnica da organização do trabalho produtivo. Sua condição de existência é um espaço no qual possa se manifestar, isto é, deve existir um receptáculo capaz de acolher esta divisão, de forma não só a possibilitar sua perpetuação, mas também ajudar a perpetuála. 0 espaço, portanto, é produto e produtor dessa divisão.

o espaço como produto (mercadoria) tem ganhado ainda mais relevância dentro do capitalismo financeiro. Sucedendo o capitalismo industrial, baseado na produção e captura de mais-valia, o capitalismo financeiro baseia-se nos juros, na renda e nas 
mercadorias fictícias. A terra e o dinheiro se instrumentalizam e se transformam, aquela em espaço e este em capital. Reinventam-se dentro do já privilegiado direito da propriedade privada e rendem a seu detentor não só o monopólio da privação do lugar, mas o da conversão do lucro extra em renda, seja ela extrativa, fundiária ou imobiliária, como manifestação de um duplo-monopólio'.

4 A produção do espaço se torna o centro de um grande embate. Se o espaço urbano é o palco do enfrentamento, da luta de classes, se torna também o motivo desta luta. Não que a disputa pelo espaço seja algo novo na história da humanidade. Não o é. Mas a busca por novas maneiras de incorporá-lo na lógica de reprodução de capital fazem com que esta luta ganhe cada vez mais relevância, dentro de um contexto de profundo contraste social entre proprietários e não proprietários e, também entre aqueles que possuem acesso aos valores de uso da cidade e aqueles marginalizados no espaço urbano.

\section{A produção do espaço capitalista global}

5 Em 'A cidade do capital' Lefebvre busca demonstrar a presença da cidade no pensamento de Marx e Engels, investigando se o elemento 'cidade' estava presente nos escritos dos dois autores, mesmo que indiretamente. Faz isso recorrendo à diferentes obras e à uma história da formação do capitalismo e da divisão social do trabalho, o que corresponde a uma história da formação das cidades, ou da "vida citadina". Lefebvre passa pela ideia de separação entre cidade e campo partindo de uma divisão de trabalho 'quase natural' ou 'biológica' para a decorrente organização do trabalho em relações escravistas. Analisa o papel da cidade e da divisão do trabalho na Antiguidade e na Idade Média, onde há, segundo ele, uma 'inversão das relações' entre cidade e campo e discute a ideia de produção total, tomando as acepções ampla e estrita do termo produção e afirmando que "a consciência é, portanto, um produto (social)" (Lefebvre, 1999a, p.45).

6 O que nos interessa em todo esse percurso é a cidade (o espaço). Sua oposição ao campo, neste caso, nos ajuda a afirmar a cidade como o local essencial da luta de classes e ao mesmo tempo resultado dessa luta. "É como se a cidade reunisse efetiva e concretamente as duas acepções do termo central, a produção" (ibidem, p.48), a saber, a produção concreta e material (estrita) e a produção de ideias, do consciente, de obras (ampla). Isto porque a cidade "concentra não só a população, mas os instrumentos de produção, o capital, as necessidades, os prazeres" (ibidem, p.49). É a cidade a base de toda a atividade humana, porém fruto ela mesma dessa mesma atividade. E se à essa atividade corresponde uma divisão (social do trabalho), ao espaço e à consciência também correspondem essa divisão.

"A separação das classes é ao mesmo tempo ilusória e muito real. Ilusória porque elas figuram na mesma sociedade, no mesmo 'todo' que se sistematiza; além disso, há somente uma fonte de riqueza social. Real, porque elas existem socialmente e praticamente numa separação, mantida como tal, que vai até ao conflito. Onde se passa essa metamorfose capital (mais exatamente: é ela que faz o capital e o capitalismo)? Na indústria e na vida citadina" (ibidem, p.35)

7 A transição campo-cidade (feudal-capital) evidencia espacialmente no urbano a nova divisão social do trabalho imposta pelo capitalismo. Essa transição se baseia na expropriação dos camponeses, tanto de suas terras quanto de seus meios de produção. "A relação capitalista pressupõe a separação entre os trabalhadores e a propriedade das condições da realização do trabalho" (Marx, 2017, p.786). Esse processo de acumulação 
primitiva ${ }^{2}$ resulta, levada ao extremo, na separação - e luta - de classes. Têm-se aí, portanto, a base social da vida citadina, dividida entre proprietários (de terra, de meios de produção) e proletários (vendedores da força de trabalho). Essa divisão se reflete em segregação espacial, no consumo e na produção, através da diferenciação, tanto espacial como da consciência.

Podemos encontrar um paralelo à ideia da diferenciação do espaço e sua relação com a divisão social do trabalho em Neil Smith e sua teoria sobre o desenvolvimento desigual. Para Smith, o desenvolvimento do capitalismo implica numa desigualdade dialética entre diferentes espaços (e em diferentes escalas). Esse desenvolvimento consiste basicamente na 'transformação do espaço natural em espaço produzido' ou ainda, na transformação do espaço absoluto em espaço relativo (Smith, 1991, p.87).

"A diferenciação do espaço geográfico no último século é um resultado direto da necessidade, inerente ao capital, de imobilizar capital na paisagem. [...] A imobilização espacial do capital, desta maneira, é simultaneamente a produção de um espaço geográfico diferenciado. $\mathrm{Na}$ medida em que este processo de imobilização é acompanhado pela mobilidade do capital, estas tendências opostas não lançam uma diferenciação interna aleatória, mas padronizada, do espaço mundial" (ibidem, p.88, grifo próprio) ${ }^{3}$

9 A mobilidade do capital, como veremos, é questão fundamental para o capitalismo. Sua 'imobilização na paisagem', como coloca Smith, nada mais é do que investimento em capital fixo, criando infraestrutura necessária para produção e circulação de capital. A contradição iminente entre capital imobilizado e em movimento pressiona o espaço rumo a um desenvolvimento desigual: "O desenvolvimento desigual é a manifestação concreta da produção do espaço sob o capitalismo" (ibidem, p.90). A contribuição de Smith vai além da divisão social do trabalho, embora ele afirme que esta divisão é a base histórica para a diferenciação espacial. Seu argumento passa pela ideia de que a divisão social do trabalho pode ser analisada em várias escalas - desde a macro, onde questões geográficas e/ou naturais podem ser determinantes para a divisão e uma decorrente 'tendência à diferenciação' do espaço; até escalas mais aproximadas, onde, segundo ele, não há tanta relevância para esta tendência, já que "a divisão detalhada do trabalho contribui muito pouco para a diferenciação social que, por sua vez, leva a um desenvolvimento desigual" (ibidem, p.109) ${ }^{4}$. Isto porque apesar da divisão social do trabalho, existe uma 'tendência à equalização' do espaço, por conta de uma equalização das condições de produção:

"Inerente à produção global de espaço relativo, portanto, existe uma tendência à equalização das condições de produção e do nível de desenvolvimento das forças produtivas. Essa aniquilação do espaço pelo tempo é o resultado final, se nunca inteiramente realizado desta tendência. Em constante oposição à tendência à diferenciação, essa tendência à equalização e sua contradição resultante são os determinantes mais concretos do desenvolvimento desigual" (ibidem, p.114) ${ }^{5}$

Assim como o objeto de Lefebvre é a cidade, para Smith esse também passa a ser o tema central, pois "o padrão mais desenvolvido do desenvolvimento desigual ocorre de fato na escala urbana" (ibidem, p.150) ${ }^{6}$. A centralização de capital no ambiente urbano, segundo ele, é uma das mais evidentes comparada às escalas nacionais ou mundiais, pois é visível através das diferenciações no espaço da cidade e da presença da renda da terra e do rent gap, onde temos de maneira clara o embate entre imobilidade (capital fixo) e mobilidade do capital ${ }^{7}$. Para Smith a reprodução das condições de produção do capital é fundamental e por isso ele prossegue na análise entre tendências à equalização e diferenciação. No âmago da questão, contudo, ainda está a divisão social do trabalho. 
11 Se Smith fala em aniquilação do espaço pelo tempo, temos em Harvey o uso do termo compressão, o que sugere um processo com menos intensidade, mas igual nos objetivos. Em 'A condição pós-moderna' Harvey delineia a transição para aquilo que vivenciamos de perto hoje com a ascensão e domínio do capitalismo financeiro. Essa transição se dá, segundo ele, através de uma acumulação flexível, que se opõe à 'rigidez do fordismo'. Dentre as inovações desse tipo de acumulação, cita principalmente as inovações comerciais, tecnológicas e organizacionais. Não compete a esse estudo destrinchar as razões que levaram à crise do fordismo ou do capitalismo industrial, ou ainda as particularidades dessa dita acumulação flexível. Destaco aqui, no entanto, dois pontos comentados por Harvey que julgo relevantes para se pensar a produção do espaço sob esse novo tipo de acumulação. O primeiro seriam as mudanças nos padrões do desenvolvimento desigual, que cria "um vasto movimento no emprego no chamado 'setor de serviços', bem como conjuntos industriais completamente novos em regiões até então subdesenvolvidas" (2010, p.140); o segundo a 'compressão do espaço-tempo' através do desenvolvimento das redes de telecomunicação e transporte, possibilitando não só a troca de informações como também diminuindo custos e expandindo fronteiras políticas, de comércio e de ideias num mundo progressivamente globalizado ${ }^{8}$.

Em suma, por mais que Harvey coloque estas duas condições separadas, elas são faces da mesma moeda. O deslocamento da mão-de-obra e do setor produtivo nada mais é do que uma reorganização espacial baseada na lógica do desenvolvimento desigual. Como vimos, a luta dialética entre a tendência à equalização e a tendência à diferenciação. De um lado, centros financeiros mundiais; de outro, centros produtores. Uma reestruturação da divisão social do trabalho que supõe e resulta em diferenciações espaciais. Toda essa reestruturação, no entanto, está baseada na compressão do espaçotempo, pois não seria possível sem ela. A compressão do espaço-tempo é a ferramenta para a reorganização da divisão social do trabalho e do desenvolvimento desigual. Como Harvey afirma, o controle do espaço e do tempo "sempre exprimem algum tipo de conteúdo de classe ou outro conteúdo social [...] Tanto o tempo como o espaço são definidos por intermédio da organização de práticas sociais fundamentais para a produção de mercadorias" (ibidem, p.218).

13 Penso que até aqui temos as condições para que se entenda como o espaço pode ser utilizado pelo capital como mercadoria. Elas ficam expostas na intersecção dos vários conceitos que giram em torno da questão da produção. A divisão social do trabalho é o meio de viabilizar a produção na lógica capitalista, com sua divisão ideológica e hierárquica. A cidade (o espaço urbano), é o ambiente que organiza espacialmente tanto a produção como a divisão social e, por organizar, torna-se também fruto da produção, incorporado à luta de classes. A tendência de expansão do capital, contudo, visa romper as barreiras espaciais, visa a homogeneização. Contudo, pretende romper esta barreira através da compressão espaço-tempo. A superação das barreiras favorece a lógica da produção e a centralização de capital. Temos então a tendência contrária, à diferenciação. O controle desta gangorra (see-saw, como denomina Smith), se dá pela reprodução de capital e pela renda da terra ${ }^{9}$. E daí a importância do rent gap e da organização do setor produtivo para explicar estas flutuações no espaço urbano. 0 que motiva este estudo, contudo, não é aceitar esta condição, mas sim imaginar cenários nos quais o espaço urbano possa ser pensado através da produção de valores de uso.

Em ‘A Revolução Urbana' Lefebvre nos mostra não a diferenciação do espaço, mas sim o espaço diferencial. Ele coloca a cidade como o lugar da simultaneidade entre os processos 
de formação, realização e distribuição da mais-valia, definindo-a como um lugar central no modo de produção capitalista. Mais do que isso, atribui uma questão temporal ao surgimento do pensamento urbano, uma passagem da era agrária para a era industrial e então para a era urbana, que se libertaria da cegueira do pensamento e planejamento redutores do período industrial, na qual tinha sua realidade "reduzida, de um lado, pelo rural [...] e de outro, pelo cotidiano industrial [...], cotidianidade submetida às exigências das empresas e tratada conforme a racionalidade empresarial" (1999b, p.38). Não por acaso ele atrela à ideia de desenvolvimento desigual essa ideia de tempo, afirmando que a análise a partir de cortes temporais não seria capaz de compreender as relações envolvidas

"Não somente existem simultaneidades, interaç̃es, desigualdades de desenvolvimento, pelas quais esses momentos [agrário, industrial e urbano] coexistem, não só uma tal noção de 'corte' lançaria à cegueira as relações de produção e de classes, como, de modo mais geral, os países ditos subdesenvolvidos caracterizam-se atualmente por conhecerem simultaneamente a era rural, a era industrial, a era urbana. Eles acumulam os problemas, sem por isso acumularem as riquezas" (ibidem, p.40)

15 A era urbana, para Lefebvre, deveria ser o momento no qual o "pensamento urbanístico [...] reúne os dados estabelecidos e separados pela história. Sua fonte, sua origem, seu ponto forte, não se encontram mais na empresa" (ibidem, p.44). A ideia de tempo implícita aqui é essencial para que a reflexão acerca da sociedade urbana não seja fragmentada. Além disso, "o espaço-tempo urbano, desde que não seja mais definido pela racionalidade industrial [...], aparece como diferencial" (ibidem, p.45). Sendo assim, Lefebvre propõe três categorias de espaço: iso-topia, hetero-topia e u-topia ${ }^{10}$. Essas proposições têm como objetivo superar a mentalidade industrial sobre o urbano, superar as condições de exploração que acarretam nos espaços desiguais, num novo campo (o urbano). Ele afirma que, assim como o industrial revela as contradições de seu anterior (agrário, feudalismo) "o urbano revela o industrial, que aparece como hierarquia reforçada por uma refinada exploração [...] A atividade organizadora dos 'decisores', apoiada pelos que detêm e gerem os meios de produção, opõe-se nitidamente à passividade dos ‘sujeitos' que aceitam essa dominação” (ibidem, p.50).

16 A superação do pensamento industrial sobre o urbano para Lefebvre, ou seja, a superação da cidade como centro de formação, distribuição e realização da mais-valia, passa justamente pela ideia de um novo espaço-tempo - o espaço-tempo diferencial. Esse espaço-tempo não é a busca por sua compressão, ou aniquilação, ou a superação do espaço através do tempo. É na verdade a busca pelo domínio do tempo através do espaço

"No curso deste vasto processo de transformação, o espaço revela sua natureza, aquilo que sempre foi: a) um espaço político, lugar e objeto das estratégias; b) uma projeção do tempo, reagindo sobre ele e permitindo dominá-lo, e, por conseguinte, atualmente, explorá-lo até a morte" (ibidem, p.50)

Que dessa transformação o espaço urbano resulte no espaço social, temos a cidade pensada através de seu valor de uso. As diferentes 'topias' propostas por Lefebvre não são espaços de diferenciação ou desiguais. A dominação do tempo através do espaço serve de ponto de partida para pensar alternativas à mercantilização do urbano. 


\section{As mercadorias fictícias e o antivalor} procura se perpetuar através do tempo e superar barreiras. Ele tensiona o espaço, a tecnologia, as condições sociais. Harvey afirma que o capital é valor em movimento e que "uma pausa ou redução na velocidade desse movimento, por qualquer razão que seja, significa uma perda de valor" (2018, p.80). Logicamente, o contrário também é válido, ou seja, "acelerar o tempo de rotação do capital é um elemento fundamental para alavancar a produção de valor" (ibidem, p.81). Estamos aqui retomando, portanto, a ideia de Smith, de oposição entre o capital imobilizado (fixado) ou móvel. Esse capital desvalorizado por seu não movimento é o antivalor. Diretamente antagônico ao valor, o antivalor pressupõe o freio no movimento eterno e cíclico da reprodução de capital. Por mais que esteja incorporado nesta lógica ${ }^{11}$, "o antivalor constitui o solo subterrâneo do qual o anticapitalismo pode florescer, tanto na teoria quanto na prática" (ibidem, p.84). Gostaria então de seguir alguns pontos:

i) O primeiro ponto passa pelo conceito do capital fictício, primordial na economia baseada no sistema de crédito. Segundo Harvey, este sistema de crédito surge como um resgate do capital morto e desvalorizado - antivalor - que é o dinheiro entesourado. Para que se mantenha o ritmo do movimento do capital, o crédito reinsere neste movimento um capital que estava parado, reproduzindo-se então na forma de juros e criando um sistema de empréstimos e dívidas:

"o capital criou o endividamento como antivalor para solucionar problemas específicos, como o perigo do entesouramento excessivo quando se lida com diferentes tempos de rotação do capital em diferentes indústrias. 0 poder do antivalor foi usado para liberar todo o valor dormente e garantir a continuidade tanto quanto fosse possível" (ibidem, p.87)

$\mathrm{Na}$ história do capitalismo e da humanidade, no entanto, esse mecanismo não é necessariamente novo. o problema surge quando todo o funcionamento do capitalismo mundial está baseado neste sistema, o que ocorre com a ascensão do financeiro no capitalismo do século XXI, já que "uma acumulação irrestrita de capital fictício poderia implicar que se apaga 'até o último rastro toda a conexão com o processo real de valorização do capital"' (ibidem, p.90). Isto significa que a sociedade não se baseia mais na produção concreta e material (o sentido estrito colocado por Lefebvre), mas sim no fetiche do capital fictício e na produção do consciente (o sentido amplo).

O foco na questão do endividamento é essencial para uma crítica à forma capitalista de produção do espaço, justamente porque esta também se baseia no capital fictício. 0 poder deste capital fictício é justamente o de não existir materialmente, o que permite a transformação de qualquer coisa em mercadoria, tanto bens e serviços básicos, como a arte, a ciência e o espaço. Se a mágica da reprodução do dinheiro pelo dinheiro aparece como ideal de justiça e segurança para a sociedade, por consequência, qualquer elemento de nossa vida torna-se mercantilizável.

Segundo Marx, uma coisa só pode ser mercadoria se possui valor de uso e valor de troca. Ainda, o fetiche da mercadoria consiste na reificação das relações sociais envolvidas na sua produção, com o obscurecimento do tempo de trabalho abstrato realizado na sua materialidade ${ }^{12}$. A mercadoria, portanto, implica numa produção com o objetivo futuro de satisfazer uma necessidade humana (valor de uso), que realizará a reprodução de capital na troca com outra mercadoria (valor de troca), onde as 
equivalências poderiam ser equiparadas pela quantidade de tempo de trabalho envolvida nessa produção (valor). Marx foca, dessa maneira, na questão do trabalho e se preocupa em evidenciá-lo.

O mundo das mercadorias, contudo, pode ser visto de uma maneira diferente da aproximação de Marx numa questão específica. Em 'A grande transformação' Polanyi passa a analisar como se constituem os mercados e quais as consequências para a sociedade da instauração de um mercado global auto-regulável. Na sua análise sobre esta economia, percebe que para que ela exista, deve "compreender todos os componentes da indústria, incluindo terra, trabalho e dinheiro". Essa condição já apresenta uma dificuldade, pois o trabalho e a terra não são nada mais do que "os próprios seres humanos nos quais consistem todas as sociedades, e o ambiente natural no qual elas existem. Incluí-los nas leis de mercado significa subordinar a substância da própria sociedade às leis do mercado" (1980, p.84).

Para Polanyi existe um ponto crucial nessa análise, que consiste basicamente no conceito do que é mercadoria. Para ele "o trabalho, a terra e o dinheiro obviamente não são mercadorias [...] Nenhum deles é produzido para a venda. A descrição da terra, do trabalho e do dinheiro como mercadorias é inteiramente fictícia" (ibidem, p.84-5). Trabalho, terra e dinheiro, portanto, constituem-se como mercadorias fictícias. Se a grande dificuldade da instauração de um mercado é subjugar as três não mercadorias porque significaria 'subjugar a substância da sociedade', Polanyi é enfático quanto as consequências:

"Permitir que o mecanismo de mercado seja o único dirigente do destino dos seres humanos e do seu ambiente natural, e até mesmo o árbitro da quantidade e do uso do poder de compra, resultaria no desmoronamento da sociedade [...] nenhuma sociedade suportaria os efeitos de um tal sistema de grosseiras fiç̧ões, mesmo por um período de tempo muito curto, a menos que a sua substância humana e natural, assim como a sua organização de negócios fosse protegida contra os assaltos desse moinho satânico" (ibidem, p.85-6)

O moinho satânico de Polanyi é um cenário cíclico de crise causada pelo subjugamento das mercadorias fictícias às leis do mercado, onde os seres humanos 'morreriam vítimas de um agudo transtorno social', a natureza seria destruída e o próprio mercado acabaria com o poder de compra "pois as faltas e excessos de dinheiro seriam tão desastrosos para os negócios como as enchentes e secas nas sociedades primitivas" (ibidem, p.85). Apesar do teor apocalíptico de suas previsões, qualquer semelhança com a realidade não seria mera coincidência.

Não queremos aqui iniciar uma discussão sobre a ficção, mas sim assinalar que a aparência desses três elementos como mercadoria é uma construção (produção) social. o espaço urbano, nesse sentido, aparece como produto potencialmente híbrido. Dependendo de suas condições de produção o espaço urbano reúne a construção (edifício, produzido por relações mercantis, que envolvam produção de mais-valia) e a base em que está implantado, ou seja, a terra. Mercadoria sobre mercadoria fictícia. Seu caráter híbrido já apresenta uma peculiaridade, pois implica na presença de preço de monopólio ${ }^{13}$. Contudo, é seu papel como ativo imobiliário, no capitalismo financeiro, que se torna relevante:

“O que está em jogo nessas negociações [transfiguração de mais-valia em renda da terra e lucro] é tradicionalmente a realização da renda e do lucro, e para isso, em tais negociações o rendimento imobiliário rentista se distinguiu do lucro industrial do empresário da construção. Atualmente, ao mesmo tempo que este rendimento 
rentista se distingue do lucro, tende a se aproximar da forma de juros dos ativos financeiros" (Pereira, 2018, p.449) ${ }^{14}$ economia de tempo. 0 capital, em nome de uma agilidade no resgate do antivalor, para retomar seu necessário movimento, faz com que o sistema de crédito seja expandido. 0 endividamento não se faz presente 'apenas' nos empréstimos de dinheiro, nas relações D-D', na reprodução de capital pelo capital. Ele se faz presente nos meios produtivos, viabilizando adiantamentos na produção: na aquisição de matérias primas, no investimento em capital fixo; e a ele fica subordinado também o consumo, na forma de crédito. A economia por endividamento assume papel principal no funcionamento do capitalismo. E o que ela esconde? Seu caráter fictício, sua desconexão com o processo de valorização. Se a pista de Lefebvre era uma dominação do tempo através do espaço, o caminho da financeirização e do endividamento são exatamente o contrário. Estes favorecem o tempo produtivista do capital, do resgate ágil do antivalor para que se coloque em movimento. A negação desta lógica, contudo, poderia indicar o caminho para a desmercantilização, pois

"[...] pode se constituir em um caminho capaz de reunir forças conscientes e independentes da valorização do uso dos bens urbanos opostas à apropriação predatória e alienada do mercado, e criar a possibilidade de reapropriação urbana e do uso comum dos espaços da cidade. E poderá crescer incrementando relações não capitalistas e popularmente solidárias na medida em que sustenta $o$ desenvolvimento de formas de produção do espaço não mercantis" (ibidem, p.452, grifo próprio) ${ }^{16}$

A produção não mercantil do espaço é o conceito capaz de reunir as características necessárias para um caminho rumo ao antivalor. $\mathrm{O}$ freio do tempo capitalista, que escancara a contradição entre valor e antivalor e que permite desvendar o fetiche da mercantilização e apropriação privadas do ambiente urbano, as quais, por sua vez, escondem os processos de obtenção de renda, a prática de preços de monopólio, a utilização do espaço urbano como ativo imobiliário e como legitimação de um poder de classe. o espaço urbano, isto é, a cidade, vista como uma não mercadoria, como um campo aberto à apropriação coletiva e à sua modificação através do conjunto da produção social que produz antivalor, adquire um tempo próprio, não atrelado ao tempo capitalista, com sua respectiva divisão social do trabalho, da produção e perpetuação da segregação e espoliação urbanas. A produção não mercantil e o antivalor podem nos conduzir ao espaço-tempo diferencial de Lefebvre, da era urbana, da libertação do pensamento sobre o urbano que o condena a um espaço voltado à formação, realização e distribuição da mais-valia. 
30 ii) O segundo ponto que gostaria de retomar diz respeito ao trabalho improdutivo. Harvey indica que "a busca política de uma existência não alienada implica a negação ativa e consciente da lei capitalista do valor em nossa vida individual e coletiva" (2018, p.94). Como vimos, a negação do valor é justamente o antivalor. Isso implica dizer que a busca pela não alienação passa justamente pela afirmação do antivalor como objetivo do conjunto da produção social. 0 trabalho que não produz valor, na lógica capitalista, é entendido como trabalho improdutivo, dos quais poderíamos citar o trabalho doméstico, a burocracia estatal, a força de trabalho envolvida na circulação de capital (não na produção). Vale dizer que estes trabalhos não são 'inerentemente anticapitalistas', já que seu uso "pode contribuir para aumentar o mais-valor relativo graças à redução dos custos dos bens salariais" (ibidem, p.93).

31 Os trabalhos improdutivos podem ser considerados complementares aos produtivos no funcionamento do capital. Se não estão envolvidos diretamente na circulação e reprodução de capital - como vimos, o antivalor é resgatado como valor na esfera da circulação para retornar ao ciclo de capital em movimento - podem estar inseridos numa lógica tão capitalista quanto, ao passo que contribuem para a produtividade dos trabalhos produtivos, para sua organização ou para sua desvalorização. Questionado se o trabalho improdutivo entra no cálculo do valor, Harvey pondera:

“A resposta de Marx é que eles são análogos às máquinas: não podem ser uma fonte de valor como definido pelo capital, mas são fonte de mais-valor relativo para a classe capitalista, na medida em que contribuem para a produtividade da força de trabalho." (ibidem, p.96)

Se trabalhos produtivos e improdutivos se complementam no funcionamento do capitalismo, no fundo, refletem uma lógica já conhecida, a divisão social do trabalho. Podemos separá-la em diversas categorias, em diversas escalas, como propôs Smith. Basta relembrar, contudo, que ele afirma 'a escala 'geral' da divisão social do trabalho, que opõe diferentes ramos de atividades e capitais individuais' como a responsável para o desequilíbrio entre as tendências à diferenciação e equalização e que a gradativa compressão espaço-tempo transformou a condição do proletariado, reorganizando a divisão social do trabalho em favor de uma produtividade e velocidade maiores para a circulação e reprodução do capital. A partir destes pontos é possível vislumbrar uma alternativa anticapitalista de produção do espaço, passando por um ponto essencial, o antivalor:

"O poder do antivalor precisa ser confrontado com a teoria do valor. Se, como suspeito, esse é o 'antagonismo mais profundo' oculto nas entranhas do capital que circula como valor em movimento, tornar essa contradição legível é um passo importante para enfrentar a servidão por dívida - que parece cada vez mais capaz de ditar não apenas nossas relações sociais e nosso bem-estar contemporâneos, mas também nossas perspectivas de vida futura" (ibidem, p.98)

Precisaríamos então objetivar um cenário no qual o conjunto dos trabalhos produtivos e improdutivos gere antivalor, e que esse antivalor permaneça como capital fixado, não reintegre o ciclo da circulação para se tornar capital novamente, já que "enquanto permanece fixado em sua figura de produto acabado, o capital não pode atuar como capital, é capital negado" (Marx, apud Harvey, 2018, p.81). A produção se objetiva, dessa maneira, em antimercadorias, o que implica na desmercantilização da força de trabalho. Em outras palavras: o trabalho improdutivo, que hoje organiza e auxilia o trabalho produtivo para produção de valor e obtenção de mais-valia por parte dos capitalistas, passaria a organizar o trabalho produtivo em torno de um outro objetivo - o antivalor. 
Neste caso, o controle do tempo passa das mãos do capital para as do trabalho, que não visa mais a produtividade capitalista, interessada na velocidade do caminho valorantivalor-valor. 0 domínio do tempo através do espaço é uma produção do espaço urbano focada nos valores de uso, onde não há oposição entre diferentes capitais individuais; onde não há expropriação do trabalhador e distanciamento dos meios de produção; onde ocorre a descompressão do tempo em favor do espaço; pois a riqueza social é comum. Trata-se de uma produção lenta - em detrimento do movimento dinâmico capitalista de resgate do antivalor.

\section{A divisão do trabalho na construção} exploração e dominação que ocorrem em sua produção a partir do conceito de valortrabalho envolvido no seu nível mais imediato - o canteiro. Esta análise, já consagrada pela crítica veemente de Sérgio Ferro e Rodrigo Lefevre, para citar alguns dos principais trabalhos neste sentido, traça o caminho para a interpretação de uma realidade que reflete a divisão social do trabalho em uma de suas formas mais perversas: de um lado o trabalho intelectual, de concepção, e de outro lado o seu complementar, o trabalho braçal, de execução. Oposição entre "mão e mente", da qual "resulta inevitavelmente a alienação que se apodera do trabalho vivo, posto que dominação, exploração e alienação são conceitos cujo conteúdo real é um só" (Bicca, 1984, p.22).

Em 'O canteiro e o desenho' Sérgio Ferro procura traçar o caminho que liga o desenho arquitetônico à exploração do operário e à reprodução de capital, assumindo desde o princípio o caráter mercantil do edifício, já que "todo e qualquer objeto arquitetônico, entre nós, é um dos resultados do processo de valorização do capital” (2006, p.106). o ponto principal para ele é a relação heterônoma existente naquele que constrói, já que segue um plano concebido longe de seus domínios e que surge como desenho arquitetônico, o qual se transforma no "caminho obrigatório para a extração de maisvalia e não pode ser separado de qualquer outro desenho para a produção" (ibidem, p. 108), colocando assim o desenho como equivalente a qualquer outro plano necessário para o estabelecimento de relações produtivas capitalistas, ou seja, trabalho improdutivo que organiza o trabalho produtivo.

A heteronomia surge, portanto, não só como palavra que faz oposição a autonomia, mas como um conceito que contém uma grave denúncia das condições em que ocorre a produção e a reprodução da sociedade: a submissão de um indivíduo a algo que não só não lhe pertence como vontade, mas também como consciência e compreensão. Dito em outras palavras, heteronomia trata de um grau elevado de alienação, no qual o sujeito, incapaz de reagir frente ao desconhecido do condicionante social - ao que ignora, no sentido de não compreender - apenas toma como verdade esta realidade, suas convenções, suas regras, e age de acordo com o costume e não de modo consciente, mas sim socialmente obediente. Abre mão de conhecer e deixar florescer sua vontade própria por razões que podem ser diversas, mas que se aproximam mais de aceitação, da resignação do que de uma escolha. "A partir da separação entre ação e vontade determinante - separação que com outras abre a brecha para a extração de mais-valia -, o trabalho escorrega no sentido da tarefa absurda e sem conexão interna" (ibidem, p. 117) 
De todas as perversas consequências da organização social da divisão do trabalho impostas pelo capital, os elevados graus de exploração e alienação aos quais submete quem trabalha podem ser considerados os mais graves. E se buscamos algum sentido na sua continuidade, isto é, razões pelas quais a sociedade se submete à essa condição de heteronomia, a resposta estará no próprio desenvolvimento do valor e sobrevida das condições de reprodução do capitalismo:

"Não basta que as condições de trabalho apareçam num polo como capital e no outro como pessoas que não têm nada para vender, a não ser sua força de trabalho. Tampouco basta obrigá-las a se venderem voluntariamente. No evolver da produção capitalista, desenvolve-se uma classe de trabalhadores que, por educação, tradição e hábito, reconhece as exigências desse modo de produção como leis naturais e evidentes por si mesmas [...] Para o curso usual das coisas, é possível confiar o trabalhador às 'leis naturais da produção' isto é, à dependência em que ele mesmo se encontra em relação ao capital, dependência que tem origem nas próprias condições de produção e que por elas é garantida e perpetuada" (Marx, 2017, p. 808-9)

Se heteronomia passa pela ideia de um indivíduo respeitar as leis que lhe são exteriores, a confiança do trabalhador 'às leis naturais da produção' não pode ser outra coisa. E perceba-se, Marx fala em educação, tradição e hábito: três elementos que surgem como essenciais para que essa dominação seja continuada. 0 capital se impõe não só através da expropriação da classe trabalhadora, mas como uma ideia, uma força, um modo de vida do qual não parece ser possível - ou nem necessário - escapar. 0 sujeito fica, portanto, destituído porque submetido à ausência de autonomia, de maneira consciente ou não. Nas palavras de Gorz, sua autonomia é retirada de maneira coercitiva 'direta ou velada' 1 .

$\mathrm{Na}$ análise da produção das mercadorias, uma das contradições evidentes deriva justamente da divisão social do trabalho: a contradição entre produção coletiva e apropriação privada. $\mathrm{Na}$ análise de Harvey, a grande chave para esta apropriação privada ocorrer está na distância ou na contradição com a qual "o dinheiro representa e simboliza o trabalho social (valor)" (2014, p.66). Dentro do capitalismo financeirizado do século XXI a divisão social do trabalho assume uma posição de ainda maior importância na produção de desigualdade, porque se promovem ainda mais a submissão dos trabalhos manuais aos de caráter intelectual, dado o avanço tecnológico e da informática, por exemplo. A intensificação da divisão social do trabalho, portanto, tensiona ainda mais o mundo da produção das mercadorias, no sentido do trabalho produtivo manual e/ou braçal, elevando a contradição entre a apropriação privada e riquezas coletivamente produzidas a níveis talvez mais desiguais do que no capitalismo industrial ${ }^{18}$. As expropriações constantes aos trabalhadores, resultantes dessa contradição, estão no âmago do funcionamento do sistema, numa grande cadeia de expropriações.

Esse poder de classe presente na estrutura da sociedade se faz presente também na questão da construção, o nível imediato da produção ao qual estamos nos debruçando. Em suas definições sobre o 'espaço social' Lefebvre trabalha a questão da produção coletiva da riqueza comum no sentido da distinção entre obra e produto. Para ele obra e produto se mesclam socialmente e o que propõe é justamente uma junção dialética entre os dois conceitos, tentando realçar dessa forma a questão do trabalho e da produção numa obra coletiva:

“Não há, portanto, nenhuma razão para estabelecer uma distinção radical entre a obra de arte e o produto até pleitear a transcendência da obra. Procedendo assim 
deixamos intacta toda a esperança de reencontrar uma relação dialética a partir da qual a obra resulta ser, em certo sentido, inerente ao produto enquanto que o produzido não devora a criação na acumulação repetitiva." (Lefebvre, 2013, p.133) ${ }^{19}$

41 A importância da junção entre obra e produto de Lefebvre se revela quando pensamos na construção coletiva ou comunitária da sociedade e no conjunto de riquezas fruto da produção coletiva desta. Indissociável de seus significados e beleza está, sempre, a questão do trabalho. 0 processo produtivo, as relações de produção, a força de trabalho empregada: eis o que construiu a história da humanidade. A apropriação privada de tais riquezas, sejam quais forem, aparece como absurda, ainda mais se não ligadas a nenhum processo produtivo. Se como vimos, a acumulação por expropriação, fruto da divisão social do trabalho privilegia a formação de uma classe dominante por separar os trabalhos intelectuais dos trabalhos manuais, a hipótese de Lefebvre se torna um caminho possível para uma aproximação entre os dois mundos, reconectando a criação à produção.

42 Talvez não seja exagero supor que a situação do elo mais fraco nessa corrente não tenha mudado drasticamente desde a crítica feita por Sérgio Ferro nos anos 1960, principalmente no sentido de uma produção coletiva de trabalho livre. A situação do operário do canteiro segue sua sina de exploração e alienação, não superando a heteronomia que lhe é imposta. Já no lado supostamente dominante, não se pode dizer o mesmo. Seja porque está imerso na ideia de obra e não produto, seja porque está contraditoriamente e realisticamente impelido/impedido de exercer a sua função social, o arquiteto trabalha cada vez mais submetido ao capital, seguindo a 'razão econômica' em sua função, o que se resume à criação de fetiches que possibilitem extração de maisvalia ou até mesmo a incorporação de paradigmas antes críticos na lógica capitalista ${ }^{20}$. Desse trágico destino histórico de uma profissão se depreende um quadro de situações em que as diferentes formas de produção do espaço condicionam social e politicamente a inserção da figura profissional do arquiteto.

43 Sendo assim, o que se propõe neste contexto de produção não mercantil objetivado neste estudo são relaçães de produção do edifício que sejam capazes de superar a heteronomia - do operário e do arquiteto - em favor da reconexão proposta por Lefebvre entre obra e produto, resultando num canteiro de obras de relações horizontais e emancipadoras. A divisão social do trabalho, desta maneira, não aparece na forma ideológica e hierarquizada que favorece a reprodução do capital - e a perpetuação desta divisão - mas sim como divisão meramente técnica e funcional, possibilitando relações igualitárias, valorização das diversas tarefas necessárias para a produção e mútuo aprendizado entre diferentes e intercambiáveis funções. Esta transformação não apenas contribuiria para relações mais humanizadas no canteiro como também para a valorização da força de trabalho, tanto manual quanto intelectual, combatendo a cadeia de expropriações a que todos os trabalhadores assalariados estão sujeitos, e reafirmando o papel relevante e socialmente necessário dos trabalhos envolvidos ${ }^{21}$.

\section{Em vias de conclusão}

44 A não mercantilização do urbano, como ponto de oposição à lógica da produção capitalista do espaço, pode ser pensada através de espaços de resistência, de onde surge o antivalor, como capital fixado e fruto de trabalho improdutivo. As maneiras de perseguir este objetivo podem ser variadas e, assim sendo, faz-se necessária uma 
síntese de todos os conceitos aqui apresentados para que se possa vislumbrar este objetivo.

Num primeiro momento vimos que a apropriação do espaço como mercadoria é um reflexo direto do modo de produção dominante, pois traduz através das diferenciações espaciais, em um desenvolvimento desigual, uma divisão social do trabalho, ou seja, uma diferenciação social. Os capitais individuais centralizados podem ser entendidos como responsáveis para o desequilíbrio nas tendências entre diferenciação e equalização e afetam o espaço urbano ao passo que o pressionam no sentido da produção de diferenciações espaciais, favorecendo a reprodução de capital. Em outras palavras, o investimento privado no setor da construção produz edifícios-mercadoria e cria lugares acessíveis e passíveis de serem apropriados apenas àqueles que podem consumi-los via mercado.

O modo de produção, contudo, se transforma, e com essa transformação carrega uma mudança na maneira de mercantilizar o espaço. A questão do tempo e sua compressão ou aniquilação - é fundamental para compreender este processo: o espaço-tempo do capitalismo financeiro carrega consigo um enorme dinamismo para agilizar a reprodução de capital. A tendência à diferenciação dos espaços é favorecida, pois criam-se novas brechas para reprodução de capital através da produção de espaço, aumentando a rotatividade do capital e diminuindo o tempo necessário para o retorno dos investimentos empregados na construção dos edifícios. A alternativa se desenha, portanto, na dominação do tempo, fazendo com que o espaço seja produzido de maneira lenta, contrapondo-se ao ritmo frenético do capital. Visa, dessa forma, não a produção de diferenciações espaciais, mas sim o espaço diferencial.

Esta produção de ritmo lento se associa diretamente com a ideia de antivalor, pois a agilidade da qual depende a reprodução de capital passa necessariamente pelo resgate deste capital fixado. 0 que seria essa produção de ritmo lento afinal? Uma produção não mercantil. A produção do trabalho improdutivo, que objetiva o antivalor e que se constitui como o freio do capital em movimento, uma produção que não está associada ao ritmo capitalista e que possa se imaginar como emancipadora.

Tratando-se de produzir espaço, contudo, é extremamente difícil pensar em termos de produção emancipadora dadas as condições de trabalho a que são submetidos os operários encarregados da construção e das relações estabelecidas entre os envolvidos na indústria da construção. A atuação do arquiteto poderia ser determinante para estabelecer novas maneiras de construir, novas relações no canteiro de obras e aproximações entre os profissionais envolvidos. Não obstante, poderia ser determinante para uma produção que não focasse a reprodução de capital, mas sim a reprodução da força de trabalho e o desenvolvimento humano. A união destes fatores desmercantilização do urbano, produção voltada ao antivalor e o conjunto dos trabalhos improdutivos de relações emancipadoras - poderia nos guiar à uma produção não mercantil do espaço. 


\section{BIBLIOGRAFIA}

ARANTES, Pedro. Arquitetura nova: Sérgio Ferro, Flávio Império e Rodrigo Lefevre, de Artigas aos mutirões. São Paulo, Editora 34, 2002.

BICCA, Paulo. Arquiteto: a máscara e a face. São Paulo, Projeto, 1984

BUITONI, Cássia Schroeder. Mayumi Watanabe Souza Lima: a construção do espaço para a educação. São Paulo, Dissertação Mestrado FAUUSP, 2009.

FERRO, Sérgio. Arquitetura e trabalho livre. São Paulo, Cosacnaify, 2006

GALVÃo, Luís Alfredo. A crítica acrítica da razão dualista. Debate \& Crítica n.3, São Paulo, 1974, p. $135-152$

GORZ, André. Crítica da divisão do trabalho. São Paulo. Martins Fontes. 1989

HARVEY, David. Condição pós-moderna. São Paulo, Edições Loyola, 2010

. Diecisiete contradicciones y el fin del capitalismo. Quito, Editorial IAEN. 2014

A loucura da razão econômica: Marx e o capital no século XXI. São Paulo, Boitempo, 2018.

JARAMILLO, Samuel. Producción del espacio construído em Bogotá. in Capital, Estado y Vivienda en America Latina. Cidade do México, Distribuiciones Fontamara, 1987

KOURY, Ana Paula. Grupo Arquitetura Nova: Flávio Império, Rodrigo Lefevre e Sérgio Ferro. São Paulo, Romano Guerra, 2003

KOWARICK, Lucio. Escritos Urbanos. São Paulo, Editora 34, 2000.

. Viver em risco. São Paulo, Editora 34, 2009.

LEFEBVRE, Henri. A cidade do capital. Rio de Janeiro, DP\&A, 1999a

. A revolução urbana. Belo Horizonte, UFMG, 1999b

. La producción del espacio. Madrid, Capitán Swing, 2013

LEFEVRE, Rodrigo. Projeto de um acampamento de obra: uma utopia. São Paulo, Dissertação de mestrado FAUUSP, 1981

MARX, Karl. O capital: crítica da economia política, Livro III. Rio de Janeiro, Civilização Brasileira, 1980

. O Capital: crítica da economia política, Livro I. São Paulo, Boitempo, 2017

OLIVEIRA, Francisco de. A crítica a razão dualista: o ornitorrinco. São Paulo, Boitempo, 2011

POLANYI, Karl. A grande transformação, as origens da nossa época. Rio de Janeiro, Campus, 1980

PEREIRA, Paulo César Xavier. Espaço, técnica e Construção: o desenvolvimento das técnicas construtivas e a urbanização do morar em São Paulo. São Paulo, Nobel, 1968

. Mercantilización de la tierra y del trabajo:: un problema insoluble? In: Teoria, política y sociedad: reflexiones críticas desde América Latina [S.l: s.n.], 2018

SMITH, Neil. Uneven Development: nature, capitalism and the production of space. Oxford, Blackwell. 1991 


\section{NOTAS}

1. 0 duplo monopólio aparece por se "considerar dois aspectos: a exploração da terra com o fim de reprodução ou de extração, e o espaço, elemento necessário a toda produção e a toda atividade humana. E a propriedade fundiária cobra seu tributo nos dois domínios. A procura de terrenos para construir aumenta o valor do solo na função de espaço e de base, e ao mesmo tempo faz acrescer a procura de elementos da terra que servem de material de construção" (Marx, 1980, p.888)

2. ver 0 capital, cap. 24: A assim chamada acumulação primitiva.

3. tradução livre

4. tradução livre

5. tradução livre

6. tradução livre

7. Nesse conceito fica evidenciado como o investimento em capital fixo (infraestrutura urbana) pressiona o espaço em direção à diferenciação. $O$ gap está justamente onde há acúmulo de capital fixo, e consequentemente o capital potencial a ser realizado aumenta exponencialmente. A busca pela realização deste capital invariavelmente leva a produção de espaços de diferenciação.

8. Ver Harvey, A experiência do espaço e do tempo, em A condição pós-moderna 9. 0 que comanda as ações dentro do capitalismo é a busca por rentabilidade. Quando o cenário é favorável à expansão, o espaço tende ao homogêneo e concentra-se na realização da renda da terra. Quanto o cenário torna-se favorável à centralização, se produzem enclaves heterogêneos, concentrando-se na realização da reprodução de capital.

10. Ver Lefebvre, A revolução urbana, p.45-6

11. "o antivalor não é um acidente infeliz, o resultado de um erro de cálculo, e sim uma característica intrínseca e profunda da própria natureza do capital: 'se por meio do processo de produção o capital é reproduzido como valor e valor novo, ele é ao mesmo tempo posto como não valor, como algo que primeiro tem de ser valorizado pela troca" (Harvey, 2018, p.80)

12. Ver Karl Marx, 0 capital, cap. 1 item 4: 0 caráter fetichista da mercadoria e seu segredo 13. 0 preço de monopólio existe porque existe a renda da terra. 0 preço de produção é a soma do custo de produção somada à uma taxa de lucro médio, que garante ao capitalista a rentabilidade de seu empreendimento. No caso da construção, por existir a propriedade privada da terra, uma parte do preço do produto deve-se converter em renda da terra, parte devida ao proprietário. Para que não haja dedução de sua taxa de lucro, o capitalista então adiciona a renda da terra à equação. Dessa forma, preço de produção somado à renda da terra nos dá o preço de monopólio.

14. tradução livre

15. "São duas coisas a distinguir: 1) ou a renda deriva de preço de monopólio por haver dela independente preço de monopólio dos produtos ou do próprio solo, ou 2) os produtos se vendem a preço de monopólio por existir renda" (Marx, 1980, p. 890)

16. tradução livre

17. Gorz, 1973, p.11

18. Para ilustrar é possível citar o caso de grandes marcas mundiais de produtos como roupas ou eletrônicos que separaram suas sedes de escritórios, localizadas em países centrais, de suas sedes produtivas, em países subdesenvolvidos. Os níveis de remuneração e de qualidade de vida diferem de maneira gritante nos dois extremos, e a 
acumulação de riqueza não se dá no lado produtivo. Nos locais onde se concentra a produção, os países subdesenvolvidos, além da exploração da sua força de trabalho, os trabalhadores ficam sujeitos a toda sorte de espoliação, num contexto em que se exerce forte pressão do capital sobre as políticas e economias locais - leis trabalhistas, regulamentação de créditos, acesso a terra, mobilidade urbana, saúde, etc. - resultando em constantes expropriações do trabalhador. Nos países sede, desenvolvidos, mercadorias fictícias possibilitam o acumulo de capital.

19. tradução livre

20. Dentro deste tema Pedro Arantes discorre sobre um momento cuja lógica continua sendo atual: "É como se a crítica de esquerda ao fordismo acabasse sendo adotada pelo capital nas suas novas formas de organização técnica do trabalho, só que com o sentido inverso: a seu favor" e continua "No caso da arquitetura Nova, poderíamos afirmar que as instalações aparentes, os azares da matéria resistente moldada pelo operário, a rusticidade das casas, deixando à vista os rastros do trabalho humano, também teriam seu poder de crítica reduzido. Primeiro porque na experiência paulistana o concreto aparente tornou-se regra geral, estilo, e não vontade de denúncia do trabalhador.

Segundo [...] o concreto aparente revela um caráter épico da construção que não é a epopeia da classe operária rumo à revolução" (2002, p.124-26)

21. Neste sentido, constituem um referencial do imaginário para este trabalho a tese de mestrado de Rodrigo Lefevre, Projeto de um acampamento de obra: uma utopia, as propostas de Mayumi Watanabe para construção de escolas com participação popular pela Conesp, e a atuação do CEDEC, em Sâo Paulo, no início dos anos 1990 (Ver Buitoni, Mayumi Watanabe Souza Lima: a construção do espaço para a educação)

\section{RESUMOS}

A produção do espaço urbano - condicionada às relações de reprodução de capital, em velocidades cada vez maiores, e de exploração da força de trabalho, organizada convenientemente pelo trabalho improdutivo dos que o projetam - acentua o conflito de classes em seu próprio terreno, modificando o tecido social que ocupa e acessa seus valores de uso de acordo com conveniências e viabilidades econômicas. $O$ antivalor pode ser a interrupção deste ciclo, atuando como o freio essencial para que se imagine um outro cenário, o da produção não mercantil do espaço.

The production of urban space - conditioned to the reproduction of capital, at ever increasing speeds, and the exploitation of the labour power, conveniently organized by the unproductive labour of those who design it - accentuates the class conflict in its own ground, modifying the social fabric which occupies and access its use values according to economic conveniences and feasibilities. The anti-value can be the interruption of this cycle, acting as an essential brake to imagine another scenario, that of the non-mercantile production of space.

La producción del espacio urbano - condicionada a las relaciones de reproducción de capital, a velocidades cada vez mayores, y de explotación de la fuerza de trabajo, organizada convenientemente por el trabajo improductivo de los que lo proyectan - acentúa el conflicto de 
clases en su propio terreno, cambiando el tejido social que ocupa y accede a sus valores de uso de acuerdo con conveniencias y viabilidades económicas. El antivalor puede ser la interrupción de este ciclo, actuando como el freno esencial para que se imagine otro escenario, el de la producción no mercantil del espacio.

La production de l'espace urbain - conditionnée par les relations toujours croissantes de reproduction du capital et d'exploitation de la force de travail, commodément organisées par le travail improductif de ceux qui la projettent - accentue le conflit de classe sur son propre terrain, modifiant la tissu social qui occupe et accède à ses valeurs d'usage selon la commodité et la viabilité économiques. L'anti-valeur peut être l'interruption de ce cycle, agissant comme le frein indispensable pour imaginer un autre scénario, la production non marchande de l'espace.

\section{ÍNDICE}

Mots-clés: Production spatiale, division du travail, produits de fiction

Palavras-chave: Produção do espaço, divisão do trabalho, mercadorias fictícias

Palabras claves: Producción del espacio, división del trabajo, mercancías ficticias

Keywords: Production of space, labour division, fictional commodities

\section{AUTOR}

\section{RENAN DOS SANTOS SAMPAIO}

Arquiteto e Urbanista. Universidade de São Paulo. Faculdade de Arquitetura e Urbanismo -

FAUUSP. e-mail: renan.sampaio@usp.br 